\title{
The Fertility Related Behavior of Mexican American Adolescents
}

\author{
Constance Lindemann \\ and \\ Wilbur Scott \\ University of Oklahoma
}

\begin{abstract}
Data from a clinic sample of pregnant adolescents are analyzed for differences in fertility related variables between Mexican American and non-Mexican. The independent variables are birthplace, ethnicity, and exposure to U.S. culture of Mexican and non-Mexican adolescents. The dependent variables are talking about sex, pregnancy, birth control, hearing about birth control, and use of birth control. The data support the hypothesis that in the process of acculturation the fertility related behavior of immigrant Mexican adolescent females is affected by the indigenous United States Mexican culture rather than by United States Anglo culture. Implications for delivery of services are discussed.
\end{abstract}

Social service and health professionals are often involved with immigrant people of different cultures in the area of family planning. This article provides a perspective, based on empirical research, on the changes that occur in the process of migration to a new area and the special conditions that influence these changes among Mexican-American adolescents in the Southwest United States. Data from a clinic sample of pregnant teenagers suggest that the delivery of fertility related services may require special attention to the distinctive features of the indigenous Mexican-American culture of the southwest United States and its effect on Mexican immigrants. This perspective supports reproductive freedom, respect for differing cultural values, and attention to the status of women and the struggle to change the status.

Authors' note: We wish to thank Dr. Willis Wingert, Director, Public Health Nurse Joan Howard, and Health Aides Juanda DeShone, Mary Jones, Dora Jordan, Becky Quiroz, and Petra Rodriquez of the Pregnant Teen Project, Los Angeles County/University of Southern California Medical Center. 
Several studies show that fertility behavior of migrants changes with increasing exposure to the culture of their new location (Long, 1970; Card, 1978). In Card's study the attitudes, knowledge, and motivations of Filipino immigrants became increasingly similar to those of the Caucasian groups as the number of years lived in the United States increased. Fertility related behavior approximated the Caucasian in frequency of contraceptive use, although the effectiveness and consistency of use was less than that of the Caucasian group. The greatest change took place in attitudes toward family size. Fewer children were desired with increasing exposure to U.S. culture.

Fertility behavior has also been shown to change with internal migration from one region to the other in the same country and in rural to urban migration (Iutaka, 1971; Kiser, Grabill, \& Campbell, 1968). Iutaka shows that rural to urban migration in Brazil changes fertility related behavior particularly if it occurs at an early age.

In the case of Mexican adolescent female immigrants to the southwest United States there are some distinct factors that may influence changes in fertility behavior. According to Alvarez the Mexican people living in this area have a unique psycho-historical background by virtue of the fact that they are indigenous people of the Southwest who were already there when Mexico lost territory to the United States. Therefore, immigrants from Mexico to the southwesteren United States come to an already established indigenous Mexican culture which " ... marks them as different from all other immigrants"' (Alvarez, 1971).

This does not imply that there are no differences between Mexican people who are indigenous to the southwest United States and Mexican people who migrate there from Mexico. For example, Dworkin has shown that Mexicans born in Mexico have more positive attitudes about Anglos and about themselves than do Mexicans born in the United States (Dworkin, 1965). But this difference also demonstrates Alvarez's theory of a unique psycho-social background which postulates that one of the contributing factors is a unique social-psychological view of self held by the indigenous U.S. Mexican people which stems from being conquered and treated as inferior by the conquering population.

The effect of being treated as an inferior on the Mexican man is that he resolves his distressed powerlessness and insignificance through the personality of the macho who compensates by exaggerated nationalism and sexism (Ramos, 1973). According to Gonzales the Mexican woman, like all women, becomes a reflection of the social position of the male, and her culture forces her into passivity and submission, but to an even greater extent than Anglo women since the greater the defeats of a people, the greater the oppression of the female members of the group (Gonzales, 1980). Gonzales goes on to say that certainly the Mexican family structure has been influenced by the United States experience, but the deep culture of the Chicano, the Mexican values, are ever present. Based on this perspective several assumptions can be made: (a) differences in culture between United States indigenous Mexicans and United States Anglos are relatively stable and long standing; (b) since culture influences behavior, differences in behavior are relatively stable and long standing; (c) reproductive behavior, like other behaviors, is influenced by culture; and there- 
fore, (d) differences in reproductive behavior between United States indigenous Mexicans and United States non-Mexicans are relatively stable and long standing.

The hypothesis in this paper is that in the process of acculturation, the fertility related behavior of immigrant Mexican adolescent females is affected by the indigenous United States Mexican culture rather than by United States Anglo culture.

This has implications for the delivery of fertility related services to Mexicans in the United States and for policy related to this service. It also provides understanding and knowledge based on empirical evidence about the fertility related behavior of Mexican-American adolescents about whom there is little in the literature on adolescent pregnancy.

\section{Definitions}

The independent variable is the culture group which has three attributes: birthplace, ethnicity, and acculturation. Birthplace is the United States or Mexico; ethnicity is Anglo or Mexican; acculturation is exposure to United States culture as determined by schooling in the United States or schooling in Mexico. Combinations of these three attributes yield the following four distinct culture groups:

1. United States indigenous Mexican: Born and schooled in the United States.

2. United States non-Mexican: Whites and blacks born and schooled in the United States.

3. Mexican immigrant: Schooled in Mexico.

4. Mexican immigrant: Schooled in the United States.

The dependent variable is fertility related behavior which is defined as behavior that is related to fertility including sex, pregnancy, and birth control. There were five variables used to measure reproductive behavior and four attributes for each of the first two variables as follows:

1. Talked about sex or pregnancy: with mother; with sister or girlfriend; with boyfriend; with professional.

2. Talked about birth control: with mother; with sister and girlfriend; with boyfriend; with professional.

3. Heard about birth control.

4. Used birth control in the past.

5. Attempted birth control use at time of conception.

Sample

The sample consisted of patients in an adolescent obstetrics clinic for obstetrical services who came directly to the clinic or were referred from various agencies in the community or from within the hospital itself. Each respondent met the following criteria: (a) pregnant; (b) under the age of 16 by the due date of delivery; and (c) compliance with the financial eligibility requirements of this medical center which meant that all were financially underprivileged. This automatically served as a control for age and socioeconomic status.

While the sample is not representative, which limits generalizability, it is likely that it reflects the adolescent pregnant population of the area. The clinic is in a large 
TABLE 1

Selected Sample and Subsample Characteristics

\begin{tabular}{|c|c|c|c|c|c|}
\hline Characteristic & $\begin{array}{l}\text { Total } \\
\text { Sample }\end{array}$ & $\begin{array}{l}\text { Mexican- } \\
\text { American }\end{array}$ & Anglo & Black & F-test* \\
\hline Age & 15.6 & 15.6 & 15.8 & 15.5 & 1.06 \\
\hline Age at first menses & 12.0 & 11.9 & 12.0 & 12.1 & 0.47 \\
\hline Age at first intercourse & 14.1 & 14.4 & 14.1 & 13.8 & 1.66 \\
\hline $\begin{array}{l}\text { Number of sex partners } \\
\text { ( } N \text { of cases) }\end{array}$ & $\begin{array}{c}1.1 \\
(359)\end{array}$ & $\begin{array}{r}1.1 \\
(233)\end{array}$ & $\begin{array}{r}1.1 \\
(24)\end{array}$ & $\begin{array}{c}1.2 \\
(102)\end{array}$ & 0.24 \\
\hline
\end{tabular}

$* p>.05$ for all F-tests

medical center in an area with an indigenous Mexican population and culture and where many immigrants from Mexico now reside. The medical center is commonly used for primary health care by the surrounding population which is largely Mexican and especially for the low income strata of that population from which the respondents come. For these reasons it is likely that pregnant adolescents who are in this clinic population reflect the population of pregnant adolescents in the community.

\section{ANALYSIS}

Mexican-American adolescent girls were compared to black and Anglo adolescent girls. Table 1 shows the similarity between the three ethnic groups on variables that might affect the independent and dependent variable in the study. An F-test shows no statistically significant differences in age, age at first menses, age at first intercourse, and number of sex partners.

Table 2 shows the comparison of fertility behaviors across groups. The left side of the table-columns one through seven-shows the percent from each group that responded affirmatively to each of the dependent variables and to each of the attributes of the dependent variables. The percents do not total to 100 since it was possible to respond affirmatively to more than one of the items. On the right side of the table, F-tests of differences in percentages between columns are presented in columns eight through eleven. Columns one (1A) and two (1B) show the percentages for Blacks and Anglos respectively. Column eight, comparing Blacks with Anglos (1A vs. 1B), shows that although there is one significant difference between these two groups on one of the attributes (talking about birth control with a professional), there are no significant differences on any of the dependent variables between Blacks and Anglos. Therefore, these two groups are combined to form the United States non-Mexican group (1). Percentages for this combined group are in column three. Columns four, five, and six show the percentages for the United States indigenous Mexican group (2A), the Mexican immigrants schooled in the United States (2B), and the Mexican immigrants schooled in Mexico (2C), respectively. Column seven shows the percentages for the three Mexican groups combined (2). Column nine compares the two Mexican immigrant groups (2B vs. 2C); column 


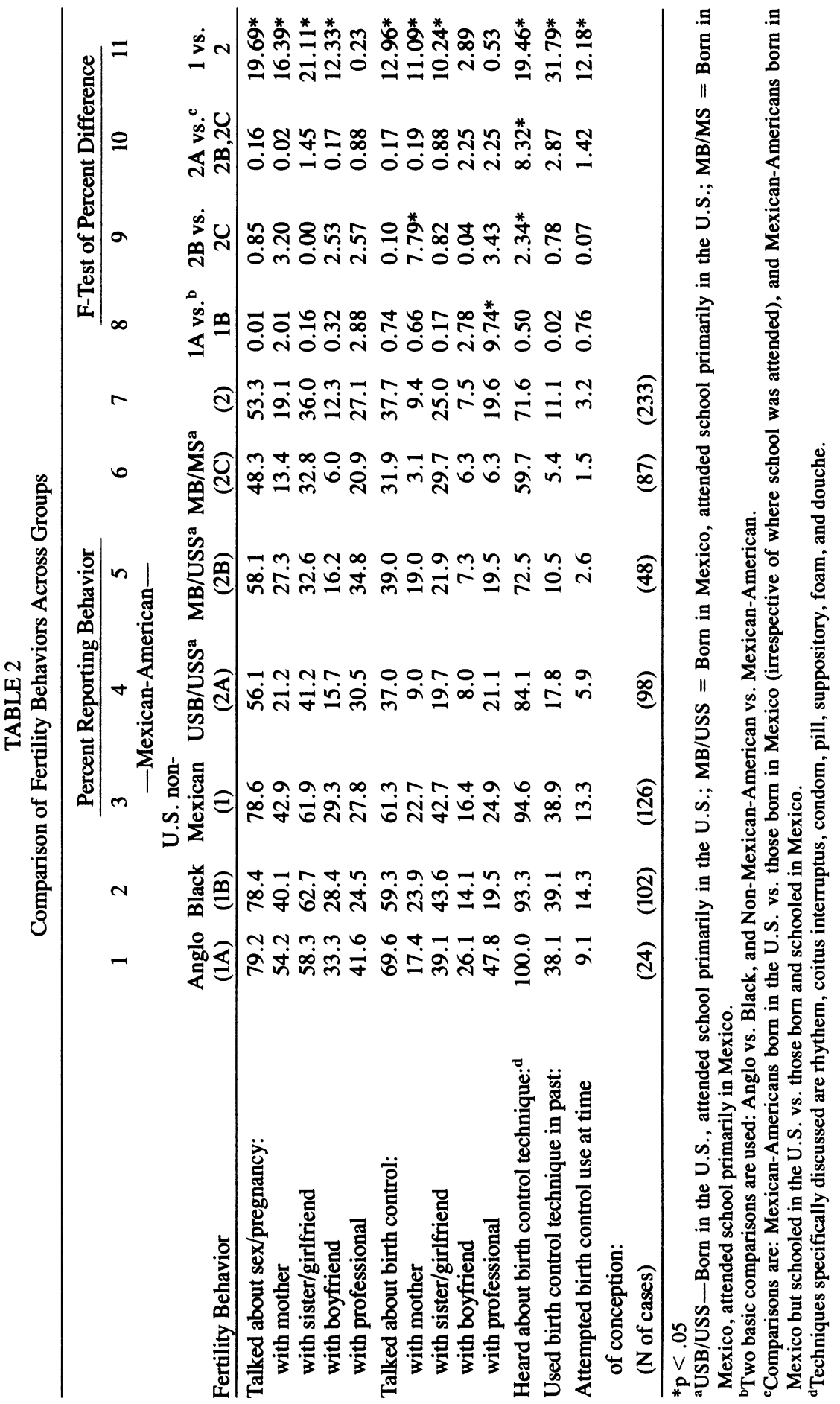


ten compares the indigenous Mexican group with the two immigrant groups combined ( $2 \mathrm{~A}$ vs. $2 \mathrm{~B}, 2 \mathrm{C}$ ); and column 11 compares the U.S. non-Mexican group with the three Mexican groups combined (1 vs. 2).

In column 9 the comparison of the two Mexican immigrant groups, the one schooled in the United States with the Mexican immigrant group schooled in Mexico (2B vs. 2C), shows no significant differences for any of the dependent variables although there is a significant difference on a single attribute of one of the variables, "talking with mother about birth control."' With this exception, both groups talk about sex, pregnancy, and birth control, heard about birth control, and used birth control to the same extent. This indicates the similarity between the two immigrant groups. In this comparison ethnicity and birthplace are common to the two groups and only exposure to U.S. culture (schooling) differs. This indicates that exposure to U.S. culture (schooling) has little, if any, influence on fertility related behavior, certainly less than ethnicity and birthplace.

In column 10 the comparison of the indigenous Mexican group and the two immigrant groups combined (2A vs. $2 \mathrm{~B}, 2 \mathrm{C}$ ) shows a significant difference on one dependent variable, "heard about birth control,' but no significant difference on the other dependent variables. This shows that the indigenous and the immigrant groups are similar, but slightly less so than the two immigrant groups compared to each other. This indicates that a change in fertility related behavior does take place because the difference between the two immigrant groups and the indigenous Mexican group is greater than the difference between the two immigrant groups. In this comparison ethnicity is common to all three groups suggesting that, since schooling has been shown to have no influence, ethnicity has a greater influence on fertility related behavior than both birthplace and exposure to U.S. culture (schooling), and birthplace has somewhat greater effect than exposure to U.S. culture (schooling). The three Mexican groups are similar regardless of differences in birthplace and schooling. Therefore, among the three Mexican groups ethnicity is the key factor in influencing reproductive behavior.

The comparison in column 11 between the three Mexican groups combined and the U.S. non-Mexican group (1 vs. 2) shows significant differences on all the dependent variables indicating a wide difference in fertility related behavior between Mexican and non-Mexican pregnant adolescents.

In summary the data show (1) little or no difference between the two immigrant groups since there are no significant differences in any of the dependent variables between these two groups; (2) somewhat greater differences between the immigrant groups and the indigenous Mexican group indicated by a statistically significant difference on one dependent variable; (3) a wide difference between the Mexican groups and the non-Mexican group indicated by significant differences on all the dependent variables; and (4) it is ethnicity, not birthplace or schooling, that affects the fertility related behavior of the immigrant groups. The conclusion based on this evidence is that Mexican adolescent immigrants do change their fertility related behavior and the change is in the direction of the United States indigenous Mexican 
group rather than the United States non-Mexican group. This supports the hypothesis that in the process of acculturation the fertility related behavior of immigrant Mexican adolescent females is affected by the indigenous Mexican culture rather than the non-Mexican United States culture.

\section{CONCLUSION AND IMPLICATIONS}

The data in this study indicate that there are distinct differences in the fertility behavior of Mexican adolescents and non-Mexican adolescents regardless of whether the Mexican adolescents were born in the United States or born in Mexico and regardless of exposure to United States culture as measured by schooling and that these differences reflect distinct differences in indigenous Mexican and nonMexican cultures in the United States. This has relevance for the study of the effects of migration on fertility and provides empirical evidence for Alvarez's theory of an indigenous Mexican culture in the Southwest United States that is distinct from Anglo culture and of a difference between Mexican and other immigrants; it also has policy implications. The delivery of fertility related services should take into account the cultural preferences of Mexican women. Mexican women should have the right to choose contraceptive methods, abortion, and sterilization without coercion from legal or medical authorities.

Pregnancy preference and childbearing patterns may be the result of social and cultural pressure and of the submission and passivity imposed on all women, especially women of an oppressed group. A change in childbearing patterns may be desirable and necessary for the liberation of Mexican-American women, but it should come as a result of the liberation movement of the Mexican-American people and the efforts of Mexican-American women to liberate themselves from traditional sex roles rather than from legal and medical authorities. That these liberation efforts and the consequent changes in Mexican-American women are taking place is evident in the writings of Hispanic women (Aragon de Valdez, 1980; Elasser, MacKenzie, \& Tixier y Vigil, 1980).

\section{REFERENCES}

Alvarez, R. The unique psycho-historical experience of the Mexican-American people. Social Science Quarterly, 1971, 52, 15-29.

Argon de Valdez, T. Organizing as a political tool for the Chicana. Frontiers, 1980, 5, 7-13.

Card, J. J. The malleability of fertility-related attitudes and behavior in a Filipino migrant sample. Demography, 1978, 15, 459-475.

Dworkin, A. G. Stereotypes and self-images held by native-born and foreign-born Mexican Americans. Sociology and Social Research, 1965.

Elasser, N. MacKenzie, K., \& Tixier y Vigil, Y. Excerpts from Las Mujeres: Conversations from a Hispanic community. Frontiers, 1980, 5, 38-47.

Gonzales, S. Toward a feminist pedagogy for Chicano self-actualization. Frontiers, 1980, 5 , 48-51. 
Iutaka, S., Bock, W. W. \& Varnes, W. G. Factors affecting fertility of natives and migrants in urban Brazil. Population Studies, 1971, 24, 55-62.

Kiser, C. B., Grabill, W. H. \& Campbell, A. A. Trends and variations in fertility in the United States. Cambridge: Harvard University Press, 1968.

Long, L. H. The fertility of migrants to and within North America. Milbank Memorial Fund Quarterly, 1970,48, 297-316.

Ramos, S. Psychoanalysis of the Mexican. In L. I. Duran \& H. R. Bernard (Eds.) Introduction to Chicano studies. New York: Macmillan, 1973.

Reprint requests should be addressed to:

Constance Lindemann

School of Social Work

University of Oklahoma

Norman, OK 73019 